\title{
Clinical significance of micrometastasis in bone marrow of patients with gastric cancer and its relation to angiogenesis
}

\author{
Yoshihiro Kakej, Yoshiniko Maehara, Kotaro Shibahara, Shota Hasuda, Eriko Tokunaga, Eiji Oki, \\ and Keizo Sugimachi \\ ${ }^{1}$ Second Department of Surgery, Faculty of Medicine, Kyushu University, 3-1-1 Maidashi, Higashi-ku, Fukuoka 812-8582, Japan
}

\begin{abstract}
:
Background. Detection of micrometastasis is an important problem of clinical significance for a better understanding and control of tumor progression, which will improve patients' survival time.

Methods. To identify micrometastases in bone marrow, an immunocytochemical assay for epithelial cytokeratin protein was performed in 106 patients with primary gastric cancer. Also, in 40 of the 106 patients, vascular endothelial growth factor (VEGF) expression and intratumoral vessel density were examined by an immunohistochemical staining method.

Results. Of the 106 patients, $22(20.8 \%)$ presented with cytokeratin-positive cells in bone marrow at the time of primary surgery. The positive findings were related to depth of invasion, peritoneal dissemination, and liver metastasis. Patients with cytokeratin-positivity in bone marrow had a higher VEGF positive rate $(73 \%$; 8/11) than did cytokeratin-negative patients $(48 \%$; 14/29). Intratumoral vessel density in VEGFpositive patients was $26.9 \pm 10.3$, which was significantly higher than that in VEGF-negative patients $(13.2 \pm 8.7$, $P<0.05)$. Thus, the presence of cytokeratin-positive cells in bone marrow was closely related to angiogenesis in the primary tumor.

Conclusions. Cytokeratin staining can be useful for identifying patients at high risk for metastasis. Prophylactic lymph node dissection, adjuvant chemotherapy, and antiangiogenic treatment may be necessary for patients with micrometastasis.
\end{abstract}

Key words: micrometastasis, angiogenesis, gastric cancer, metastasis

Offprint requests to: Y. Kakeji

Received for publication on Jan. 27, 1999; accepted on Feb. 26, 1999

\section{Introduction}

The development of metastasis in cancer patients after curative resection of primary tumor is a serious problem. The early stages of tumor progression and micrometastasis formation have been difficult to detect because of the small numbers of tumor cells against the background of many host cells. Subclinical tumor cell dissemination can be detected by immunocytological staining of cells [1,2].

Cytokeratin proteins are essential constituents of the cytoskeleton of both normal and malignant epithelial cells; hence, they can serve as reliable markers for the epithelial origin of cells [3]. The use of a monoclonal antibody against the cytokeratin component expressed by all tumor cells derived from simple epithelia facilitates the identification of one of $10^{5}$ epithelial tumor cells in bone marrow [4]. We examine disseminated tumor cells in bone marrow, as representative of a part of the tumor that can remain after surgery and which can provide direct evidence of the metastatic or disseminative potential of the tumor cells.

The mechanism of cancer cell migration from the primary lesion to the bone marrow is still unclear. Angiogenesis is closely involved in tumor progression and metastasis [5]. The level of microvessel density was shown to be correlated with hematogenous metastasis of gastric cancer [6]. We have previously reported that, in early gastric cancer, microvessel density in the primary tumor was twofold higher in patients with cytokeratin-positive cells, compared with findings in patients with cytokeratin-negative cells [7]. One of the most important factors in inducing the formation of new blood vessels is vascular endothelial growth factor (VEGF), which acts specifically on endothelial cells [8]. To clarify the relationship between angiogenesis and micrometastasis of gastric cancer, we investigated VEGF expression and microvessel density in the pri- 
mary tumor, as well as the detection of cytokeratinpositive cells in the bone marrow.

\section{Patients and methods}

\section{Patients}

This study included 106 Japanese patients with primary gastric cancer, all of whom had under gone gastrectomy, between 1994 and 1998, at the second Department of Surgery, Kyushu University Hospital, Fukuoka, Japan. A thorough histological examination was made using hematoxylin and eosin-stained tissue preparations, and the histological classification was done according to the general rules set up by the Japanese Gastric Cancer Association [9]. No patient treated preoperatively with cytotoxic drugs was included in this study.

\section{Bone marrow specimens}

Details of the procedure for obtaining bone marrow specimens are given in a previous report [4]. Briefly, preoperatively, 1- to 2-ml aliquots of bone marrow aspirates were taken from the sternum in syringes containing 100 units heparin/ml marrow, and bone marrow cells were prepared. After density centrifugation through Ficoll-Hypaque (Pharmacia Biotech AB, Uppsala, Sweden, $400 \mathrm{~g}, 30 \mathrm{~min}$ ), mononuclear cells were collected from the interphase. The cells were suspended with $0.5 \mathrm{ml}$ RPMI 1640 medium containing $10 \%$ fetal calf serum, yielding a concentration of $2 \times 10^{6} / \mathrm{ml}$, and were then smeared on glass slides and fixed with acetone $\left(30 \mathrm{~min}, 4^{\circ} \mathrm{C}\right.$ ). For immunostaining, the monoclonal antibody, CK2 (IgG1; Boehringer Mannheim, Mannheim, Germany) or CAM 5.2 (IgG2a; Becton Dickinson, San Jose, CA, USA) was used at a concentration of $0.2 \mu \mathrm{g} / \mathrm{ml}$. These antibodies recognize intracellular cytokeratin component no. 18, an intermediate filament representing the intracellular network of the cytoskeleton that is expressed in simple epithelia and nowhere else. The antibody reaction was developed using the labeled avidin-biotin (LAB) technique, and biotin-labeled antibody and alkaline-phosphatase (LAP)-labeled avidin were used sequentially. Naphthol-AS-BI-phosphate was used as a substrate of ALP and the released naphtholAS-BI was coupled with hexazotized new fuchsin. Endogenous phosphatase was inhibited by preincubation with levamisole. Cells containing cytokeratin were stained bright red. Two observers (Y.M. and Y.K.) independently examined the positivity of micrometastasis in bone marrow.

\section{Immunohistochemical staining of VEGF}

The LAB method was used for VEGF immunohistochemical staining in 40 of the 106 patients. Tumors were collected and fixed in 10\% formalin. One paraffin block contained both cancerous and adjacent noncancerous tissue, and cancerous tissue invading to the deepest level of the stomach wall was selected from all patients. Sections 5 - $\mu$ m-thick made from paraffinembedded blocks were deparaffinized in xylene and rehydrated in a graded series of ethanol. Endogenous peroxidase activity was quenched in methanol containing $0.3 \%(\mathrm{v} / \mathrm{v})$ hydrogen peroxidase for $30 \mathrm{~min}$, after which nonspecific binding was blocked by treatment with $10 \%(\mathrm{v} / \mathrm{v})$ normal goat serum in PBS for $15 \mathrm{~min}$. The primary antibody used was A-20 (Santa Cruz Biotechnology, Santa Cruz, CA, USA) A-20 is an affinitypurified rabbit polyclonal antibody raised against a 20-amino acid synthetic peptide corresponding to residues 1-20 mapped at the amino terminus of human VEGF. The sections were incubated for $2 \mathrm{~h}$ with A-20 (1:50 dilution) at room temperature, then with biotinylated goat anti-rabbit immunoglobin $\mathrm{G}$ (Vector, Burlingame, CA, USA; 1:200 dilution for 1h). After a thorough washing in PBS, peroxidase-conjugated streptavidin (Dako LSAB Kit, Dako, Carpinteria, CA, USA) was applied, followed by incubation for $30 \mathrm{~min}$. Peroxidase labelling was developed with diaminobenzidine (DAB) and hydrogen peroxidase $\left(\mathrm{H}_{2} \mathrm{O}_{2}\right)$, and nuclear counterstaining was done using Mayer's hematoxylin solution. Specificity of binding for antibody was examined by employing non-immune sera instead of specific antibody.

Cellular localization of the antigenic sites was determined by two investigators (Y.K. and S.H.) without knowledge of clinicopathological information. A double-headed light microscope was used. A positive value was recorded if more than $5 \%$ of the tumor cells expressed VEGF antigen.

\section{Microvessel staining and microvessel density (MVD)}

As an indicator of tumor angiogenesis, microvessels within the tumor tissue were counted on immunohistochemically stained sections, under a light microscope, in 40 of the 106 patients. The primary antibody used was mouse anti-CD31 antibody (Dako; diluted $1: 50$ at $4^{\circ} \mathrm{C}$, overnight) [10].

MVD was assessed with a light microscope, using the technique of Weidner et al. [11], with some modification. All the slides were scanned at a low magnification $(\times 40$ or $\times 100)$, and the area of the most dense neovascularization (greatest number of capillaries or small venules) was determined. Individual microvessel counts were made on a $\times 200$ field $\left(0.739 \mathrm{~mm}^{2}\right.$ per field $)$. Positive cells or cell clusters, clearly separate from adjacent microvessels, tumor cells, and other connective tissue elements, were considered a single, countable microvessel. Occasional immunopositive leukocytes 
were excluded on morphologic grounds. The distribution of areas of most intense vascularization was heterogeneous in each tumor. In all the samples, the mean value for the number of microvessels was calculated from five highly vascularized areas, "hot spots". These values were then assessed as the MVD for each patient's specimen. All counts were performed by the same investigator (Y.K.) and reviewed by the observer (S.H.).

\section{Statistical analysis}

Clinicopathological data were stored in an IBM 3090 mainframe computer (IBM, Armonk, NY, USA). A biomedical computer program (BMDP) was used for all statistical analyses [12]. The BMDP P4F and P3S programs were used for $\chi^{2}$ and Mann-Whitney tests to compare characteristics between groups. The BMDP P1L program was used for the Kaplan-Meier analysis of survival rates, and the Mantel-Cox test was used to test for equality of survival curves. The level of statistical significance was set at $P<0.05$.

\section{Results}

\section{Clinicopathological factors}

Twenty-two of the 106 patients $(20.8 \%)$ presented with cytokeratin-positive cells in bone marrow at the time of primary surgery. The alkaline phosphatase-stained cells in cytocentrifuge preparations appeared as red single or clustered cells, and were present at a frequency of $10^{-4}$ to $10^{-5}$ nucleated cells (Fig. 1). These cells were de-stained and confirmed to be cancer cells by Papanicolaou staining.

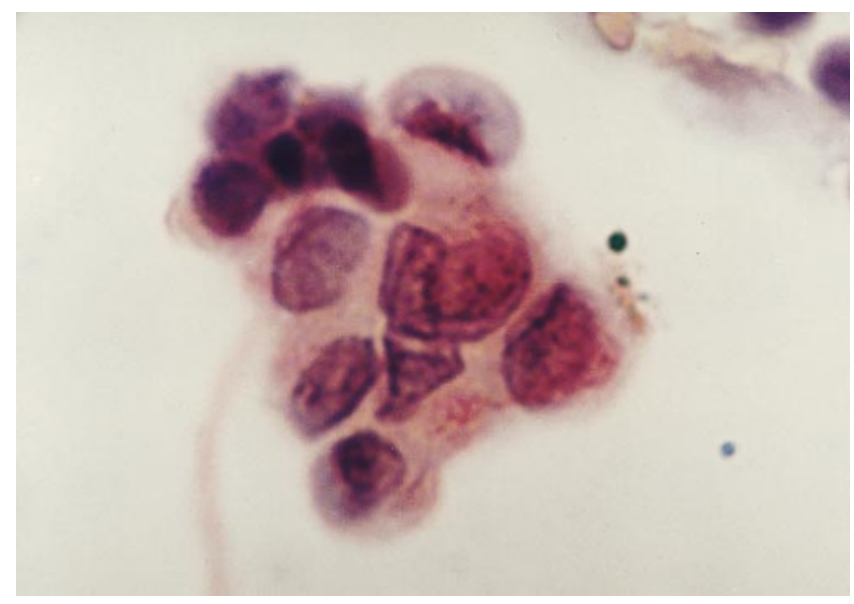

Fig. 1. Micrometastasis in bone marrow. High-power photomicrograph of bone marrow specimen with a small cluster of cells. $\times 1000$
Clinicopathological factors in patients with gastric cancer with and without cytokeratin-positive cells in the bone marrow were analyzed. Positive findings were related to depth of invasion (Fig. 2a) and to peritoneal dissemination and liver metastasis (Fig. 2b), but not to other clinicopathological factors.

\section{Relation between presence of micrometastasis and angiogenesis}

Of 40 tumors examined with anti-VEGF antibody, 22 (55\%) were VEGF-positive (Fig. 3). The mean MVD of VEGF-positive tumors was $26.9 \pm 10.3$, which was significantly higher than that in the VEGF-negative tumors $(13.2 \pm 8.7 ; P<0.05)$.

Although the difference was not significant, the positivity rate for VEGF in cytokeratin-positive patients $(73 \% ; 8 / 11)$ was higher than that in cytokeratinnegative patients $(48 \% ; 14 / 29)$ (Table 1). Microvessel density did not show differences between patients with and without cytokeratin-positive cells in the bone marrow.

Table 1. Relationship between cytokeratin-positive cells in bone marrow and VEGF expression in primary gastric cancer

\begin{tabular}{lrr}
\hline & \multicolumn{2}{c}{$\begin{array}{c}\text { VEGF expression } \\
\text { in primary tumor }\end{array}$} \\
\cline { 2 - 3 } $\begin{array}{l}\text { Cytokeratin-positive cells } \\
\text { in bone marrow }\end{array}$ & $(-)$ & $(+)$ \\
\hline$(-)$ & $15(52 \%)$ & $14(48 \%)$ \\
$(+)$ & $3(27 \%)$ & $8(73 \%)$
\end{tabular}

VEGF, Vascular endothelial growth factor

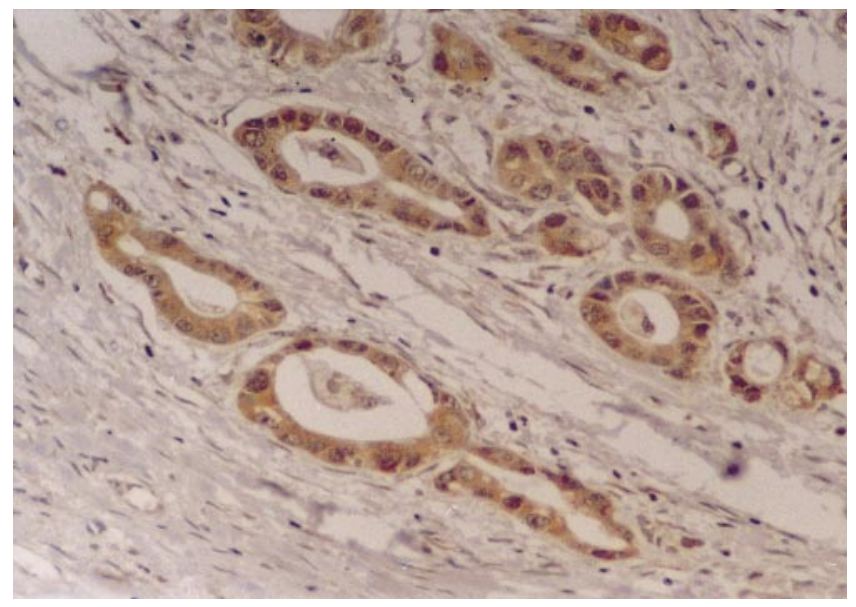

Fig. 3. Microphotography of vascular endothelial growth factor (VEGF) expression in the primary tumor. Cytoplasmic staining was recognized. $\times 200$ 


\section{Depth of invasion}

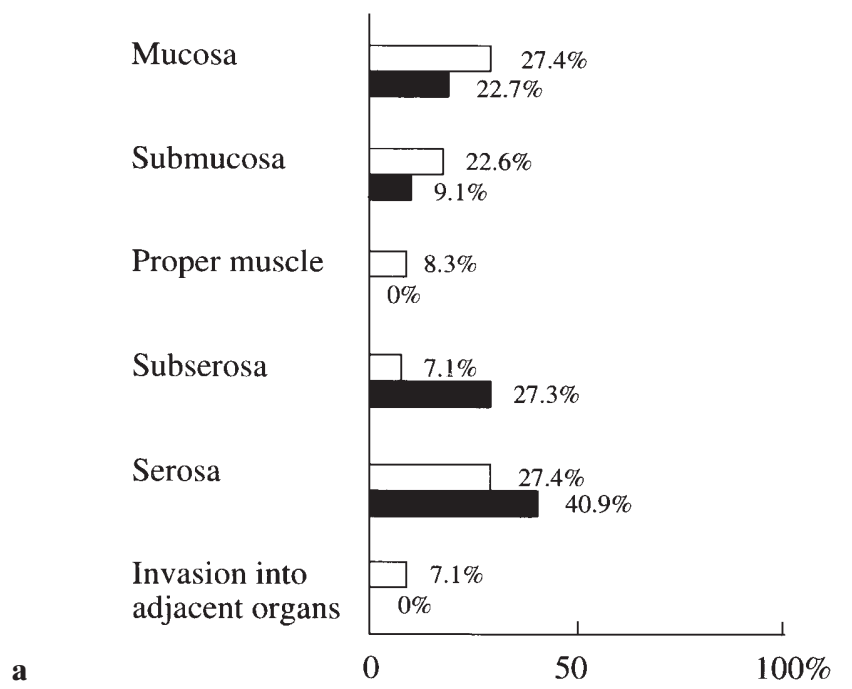

Fig. 2a,b. Clinicopathologic findings and cytokeratin-positive cells in the bone marrow of patients with gastric cancer. a Depth of invasion and cytokeratin-positive cells. b Invasion/ metastasis and cytokeratin-positive cells. White bars,

\section{Prognosis}

The overall survival curves for patients with and without cytokeratin-positive cells in the bone marrow showed no significant difference. The 3-year survival rate of patients with cytokeratin-positive cells in the bone marrow was $69.1 \%$, which was lower than that $(79.6 \%)$ of patients without cytokeratin-positive cells.

\section{Discussion}

After the liver, the skeleton is the most frequent site of distant metastasis in gastric cancer [13]. Schlimok et al. [1] reported that tumor cells were detected in bone marrow in $35 \%$ of patients with gastric cancer at primary surgery, using a cytokeratin assay with monoclonal antibody. Overt bone or skeletal metastases are rare in patients with gastric cancer; however, bone marrow is distinctly more often involved than would be expected from the clinical findings [1,14]. The apparent discrepancy between clinically rare bone metastases and the marrow micrometastases frequently detected by immunocytochemistry may be explained by the reduced proliferative behavior of the cells and their often invoked state of dormancy $[4,15]$. The capacity of the tumor cells to proliferate in the bone marrow and to manifest metastasis depends on the microenvironment. Jauch et al. [16] reported that positive bone marrow aspirations are a surrogate marker of general tumor-cell
Invasion and metastasis

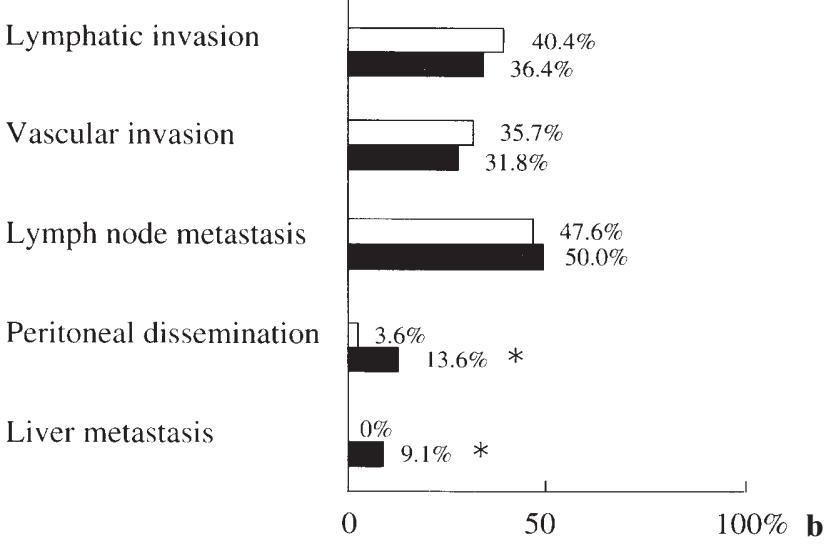

Cytokeration-negative patients $(n=84)$; black bars, cytokeratin-positive patients $(n=22)$. a $P<0.05$ cytokeratinpositive vs cytokeratin-negative for all depths of invasion. $\mathbf{b}$ $* P<0.05$

dissemination or minimal residual disease, rather than the start of metastatic growth in skeletal systems. The presence of disseminated cells in bone marrow could also indicate that cancer cells have reached the peritoneum, liver, or lung [14]. Therefore, these patients may be at a high risk for complications arising from peritoneal dissemination or liver metastasis, with no manifest metastasis in the bone marrow [17,18]. In our study, cytokeratin-positivity in the bone marrow was significantly related to peritoneal dissemination and liver metastasis. Survival time was reported to be shorter in a cytokeratin-positive group of patients with gastric cancer than in a cytokeratin-negative group $[15,16]$. Although the follow-up periods were shorter in our study, the same trend was recognized.

Vascularization is usually required for tumor cells to enter the blood circulation [6]. A high degree of tumor vascularization increases the likelihood that tumor cells will enter the circulatory system and metastasize [19]. We previously reported the relation between tumor angiogenesis and micrometastasis in patients with early gastric cancer [7]. In the present study, patients with VEGF-secreting tumors associated with high vascular density often had cytokeratin-positive cells in the bone marrow. Thus, the presence of micrometastasis in the bone marrow may be related to angiogenesis in the primary tumor. Micrometastasis was noted even in patients with mucosal gastric cancer; thus, seeding of cancer cells can occur even in early stages of the cancer. 
We previously examined dissected lymph nodes from 34 patients with node-negative early gastric cancer (who died with a recurrence) for the presence of tumor cells [20]. Of the 420 lymph nodes we examined, 15 nodes $(3.6 \%)$ and $23.5 \%(8 / 34)$ of the patients presented with cytokeratin-positive cells at the time of primary surgery. When the tumor stage was stratified according to the group of metastatic lymph nodes, the cytokeratinpositive patients were upstaged and the prognosis was poorer. It is difficult to predict precisely the presence of micrometastases in lymph nodes of early gastric cancer, based only on the macroscopic findings at the time of operation [21]. Baba et al. [22] reported that the rate of recurrence was higher in patients treated with dissection of group 1 lymph nodes than for those with dissection of group 2 or 3 nodes, in patients with nodenegative early gastric cancer. These reports also suggested the possible presence of micrometastases in lymph nodes of node-negative gastric cancer. Therefore, prophylactic lymph node dissection is expected to increase the curative rate of early gastric cancer [22]. This surgical strategy was also employed for patients with advanced gastric cancer. We previously reported that prophylactic lymph node dissection promoted increased survival time in patients with advanced gastric cancer $[23,24]$.

Adjuvant chemotherapy may be another effective treatment for micrometastasis. Okamura et al. [25] reported the possibility of micrometastasis even when resection seemed to be curative for patients with early gastric cancer. They concluded that postoperative adjuvant chemotherapy would lead to a great diminution in recurrence of cancer. Although postoperative chemotherapy is too closely associated with other prognostic covariants for it to have prognostic significance for all tumor stages [26], intensive postoperative chemotherapy, based on the characteristics of the tumor, should be designed for patients with a poorer prognosis.

As some of the new therapies for micrometastasis, antiangiogenic agents have been spotlighted. TNP-470 [27,28], anti-VEGF monoclonal antibody [29], and Angiostatin [30,31], have been considered potential therapeutic agents for controlling the progression of angiogenic tumors with a high metastatic potential. These antiangiogenic agents could be a therapeutically useful addition to cytotoxic treatments directed toward tumor cells.

In conclusion, the presence of micrometastasis in the bone marrow was closely related to angiogenesis in the primary tumor. Tumor cells in the bone marrow are indicative of the general disseminative capacity of an individual tumor. Prophylactic lymph node dissection, adjuvant chemotherapy, and the use of antiangiogenic agents seem to be effective in helping to prevent micrometastasis of gastric cancer.

\section{References}

1. Schlimok G, Funke I, Pantel K, Strobel F, Lindemann F, Witte J, et al. Micrometastatic tumour cells in bone marrow of patients with gastric cancer: methodological aspects of detection and prognostic significance. Eur J Cancer 1991;27:1461-5.

2. Juhl H, Stritzel M, Wroblewski A, Henne-Bruns D, Kremer B, Schmiegel W, et al. Immunocytological detection of micrometastatic cells: comparative findings in the peritoneal cavity and the bone marrow of gastric, colorectal, and pancreatic cancer patients. Int J Cancer 1994;57:330-5.

3. Schlimok G, Riethmüller G. Detection, characterization and tumorigenicity of disseminated tumor cells in human bone marrow. Semin Cancer Biol 1990;1:2007-15.

4. Maehara Y, Yamamoto M, Oda S, Baba H, Kusumoto T, Ohno S, et al. Cytokeratin-positive cells in bone marrow for identifying distant micrometastasis of gastric cancer. Br J Cancer 1996;73:837.

5. Folkman J. What is the evidence that tumors are angiogenesis dependent? J Natl Cancer Inst 1990;82:4-6.

6. Tanigawa N, Amaya H, Matsumura M, Shimomatsuya $T$, Horiuchi T, Murapka R, et al. Extent of tumor vascularization correlates with prognosis and hematogenous metastasis in gastric carcinomas. Cancer Res 1996;56:2671-6.

7. Maehara Y, Hasuda S, Abe T, Oki E, Kakeji Y, Ohno S, et al. Tumor angiogenesis and micrometastasis in bone marrow of patients with early gastric cancer. Clin Cancer Res 1998;4:2129-34.

8. Marme D. Tumor angiogenesis: the pivotal role of vascular endothelial growth factor (VEGF). World J Urol 1996;14:166-74.

9. Japanese Gastric Cancer Association. Japanese classification of gastric carcinoma. 2nd English ed. Gastric Cancer 1998;1:10-24.

10. Kakeji Y, Maehara Y, Ikebe M, Teicher BA. Dynamics of tumor oxygenation, CD31 staining and transforming growth factor- $\beta$ levels after treatment with radiation or cyclophosphamide in the rat 13762 mamary carcinoma. Int J Radiat Oncol Biol Phys 1997;37:1115-23.

11. Weidner N, Semple JP, Weich WR, Folkman J. Tumor angiogenesis and metastasis - correlation in invasive breast carcinoma. N Engl J Med 1991;324:1-8.

12. Dixon WJ. BMDP statistical software manual. Berkeley, CA: University of California Press, 1998:133-744.

13. Koga S, Takebayashi M, Kaibara N, Nishidoi H, Kimura O, Kawasumi H, et al. Pathological characterization of gastric cancer that develop hematogenous recurrence, with special reference to the site of recurrence. J Surg Oncol 1987;36:239-42.

14. Schlimok G, Funke I, Bock B, Schweiberer B, Witte J, Riethmüller G. Epithelial tumor cells in bone marrow of patients with colorectal cancer: Immunocytochemical detection, phenotypic characterization, and prognostic significance. J Clin Oncol 1990;8:831-7.

15. Cote RJ, Rosen PP, Lesser ML, Old LJ, Osborne MP. Prediction of early relapse in patients with operable breast cancer by detection of occult bone marrow micrometastases. J Clin Oncol 1991;9:1749-56.

16. Jauch KW, Heiss MM, Gruetzner U, Funke I, Pantel K, Babic R, et al. Prognostic significance of bone marrow micrometastases in patients with gastric cancer. J Clin Oncol 1996;14:1810-7.

17. Maehara Y, Moriguchi S, Kakeji Y, Kohnoe S, Korenaga D, Haraguchi M, et al. Pertinent risk factors and gastric carcinoma with synchronous peritoneal dissemination or liver metastasis. Surgery 1991;110:820-3.

18. Moriguchi S, Maehara Y, Korenaga D, Sugimachi K, Nose Y. Risk factors which predict pattern of recurrence after curative surgery for patients with advanced gastric cancer. Surg Oncol 1992;1:341-6.

19. Woodhouse EC, Chuaqui RF, Liotta LA. General mechanisms of metastasis. Cancer 1997;80:1529-37.

20. Maehara Y, Oshiro T, Endo K, Baba H, Oda S, Kusumoto T, et al. Clinical significance of occult micrometastasis in lymph nodes 
from patients with early gastric cancer who died of recurrence. Surgery 1996;119:397-402.

21. Okamura T, Tsujitani S, Korenaga D, Haraguchi M, Baba H, Hiramoto Y, et al. Lymphadenectomy for cure in patients with early gastric cancer and lymph node metastasis. Am J Surg 1988; 155:476-80.

22. Baba H, Maehara $\mathrm{Y}$, Takeuchi $\mathrm{H}$, Inutsuka $\mathrm{S}$, Okuyama $\mathrm{T}$, Adachi Y, et al. Effect of lymph node dissection on the prognosis in patients with node-negative early gastric cancer. Surgery 1995;117:165-9.

23. Maehara Y, Okuyama T, Moriguchi S, Orita H, Kusumoto H, Korenaga D, et al. Prophylactic lymph node dissection in patients with advanced gastric cancer promotes increased survival time. Cancer 1992;70:392-5.

24. Maehara Y, Tomoda M, Tomisaki S, Ohmori M, Baba H, Akazawa K, et al. Surgical treatment and outcome for nodenegative gastric cancer. Surgery 1997;121:633-9.

25. Okamura T, Korenaga D, Baba H, Saito A, Sugimachi K. Postoperative adjuvant chemotherapy inhibits early recurrence of early gastric carcinoma. Cancer Chemother Pharmacol 1989;23:319-22.
26. Maehara Y, Emi Y, Moriguchi S, Takahashi I, Yoshida M, Kusumoto H, et al. Postoperative chemotherapy for patients with advanced gastric cancer. Am J Surg 1992;163:577-80.

27. Kakeji Y, Teicher BA. Preclinical studies of the combination of angiogenic inhibitors with cytotoxic agents. Invest New Drugs 1997;15:39-48.

28. Teicher BA, Emi Y, Kakeji Y, Northey D. TNP-470/minocycline/ cytotoxic therapy: a systems approach to cancer therapy. Eur J Cancer 1996:32A:2461-6.

29. Kim KJ, Li B, Winer J, Armanini M, Gillett N, Phillips HS, et al. Inhibition of vascular endothelial growth factor-induced angiogenesis suppresses tumor growth in vivo. Nature 1993;362: $841-4$.

30. O'Reilly MS, Holmgren L, Shing Y, Chen C, Rosenthal RA, Moses M, et al. Angiostatin: a novel angiogenesis inhibitor that mediates the suppression of metastases by a Lewis lung carcinoma. Cell 1994;79:315-28.

31. O'Reilly MS, Holmgren L, Chen C, Folkman J. Angiostatin induces and sustains dormancy of human primary tumors in mice. Nature Med 1996;2:689-92. 